\title{
A Design of the Second Generation of UIN Sunan Kalijaga's UV Fluorescence Spectro-Imaging System
}

\author{
Frida Agung Rakhmadi ${ }^{1, *}$ Widayanti $^{1}$, Rochan Rifai ${ }^{2}$ \\ ${ }^{1}$ Physics Department, Faculty of Science and Technology, UIN Sunan Kalijaga Yogyakarta, Yogyakarta, Indonesia \\ ${ }^{2}$ PT Madeena Karya Indonesia, Yogyakarta, Indonesia \\ *Corresponding author. Email: frida.rakhmadi@uin-suka.ac.id
}

\begin{abstract}
Research on design of the second generation of UIN Sunan Kalijaga's UV fluorescence spectro-imaging system was done. The purpose of this research was to make a design of the second generation of UIN Sunan Kalijaga's UV fluorescence spectro-imaging system as a development of the first generation. This research was conducted through two steps, making a block diagram and a design of the system. The system block diagram was made using Microsoft Visio, while the design was made using SketchUp software. The result showed that a block diagram and a design of the second generation of UIN Sunan Kalijaga's fluorescence spectro-imaging system based on high power UV-LED of waveleght $395 \mathrm{~nm}$ as excitation source and webcam M-Tech WB100 as sensor was made successfully.
\end{abstract}

Keywords: UV fluorescence spectro-imaging system, high power UV-LED, webcam M-Tech WB100.

\section{INTRODUCTION}

The government and DPR RI have issued law (UU) number 33 of 2014 concerning Halal Product Guarantee (HPG). As stated in the law, HPG is a legal certainty regarding the halalness of a product as evidenced by a halal certificate. Chapter 33 states that the implementation of HPG aims: first, to provide comfort, security, safety, and certainty of the halal products availability for the public in consuming and using the product; second, increasing added value for business actors to produce and sell halal products [1].

The implementation of HPG is based on several principles. As stated in the law 33 of 2014 chapter 2, the principles of HPG implementation are protection, justice, legal certainty, accountability and transparency, effectiveness and efficiency, and professionalism. These principles must underlie all activities in HPG, one of them is detection assurance.

Detection assurance is an attempt to find and determine the existence of something. In the context of the halalness of a product, detection assurance is an attempt to find and determine the presence of haram ingredients in a product. Both efforts are achieved through measurement activities.
Etymologically, based on the online KBBI, measurement is the process, method, act of measuring. As for terminology, measurement is the process of determining the value of a physical quantity [2]. In the context of the object of haram material in a product, measurement is a process to find haram ingredients in a product and to determine its physical quantity value.

There are several types of measurement, one of which is image-based measurement. The basic principle of this measurement is to record the object image using an image instrumentation system. After the object image obtained, the image is pre-processed to eliminate unnecessary noise and information in order to ease the computation in the next stage (image processing). Furthermore, image processing is carried out to extract information from the image.

Technologically, instrumentation systems to obtain images are very diverse, ranging from simple to complex. One of image instrumentation system which is quite simple but reliable is UV fluorescence spectroimaging system.

The first generation of UIN Sunan Kalijaga's UV fluorescence spectro-imaging system was successfully developed [3]. The system was applied to distinguish between lard and beef, to analyze formalincontaminated tofu [4], to analyze borax-contaminated cilox [5], and to analyze formalin-contaminated wet 
noodles. In order to increase its effectiveness and efficiency, the system has been added with a light intensity control subsystem [6]. However, this first generation system was big size, heavy mass, and less portable. To overcome weaknesses of the first generation system above, the second generation of UIN Sunan Kalijaga's UV fluorescence spectro-imaging system needs to be made.

Before making the second generation system, it is necessary to design the system. This article intends to present a design of the second generation of UIN Sunan Kalijaga's UV fluorescence spectro-imaging system. The presence of this design will be used as a guide in making the second generation system.

\section{METHODS}

The research on design of the second generation of UIN Sunan Kalijaga' UV fluorescence spectro-imaging system was done in two steps. First step was making a block diagram of the system and second step was making a design of the system.

The system block diagram was made using Microsoft Visio software and the system design was made using SketchUp software. Making of the system design was done based on the system block diagram that was made previously.

\section{RESULT AND DISCUSSION}

The system block diagram that was made using Microsoft Visio software is shown in Figure 1. While, the system design that was made using SketchUp software is shown in Figure 2.

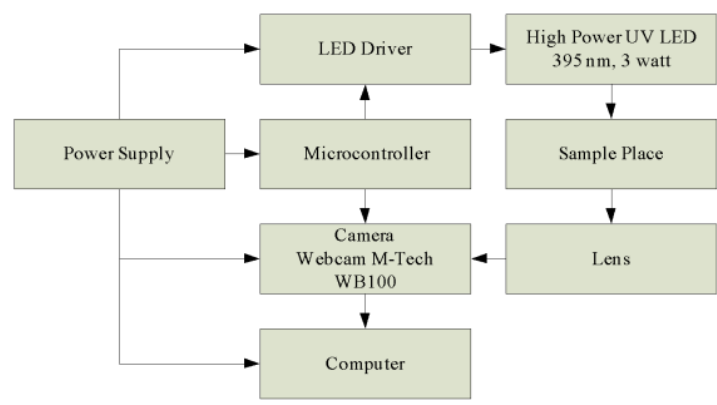

Figure 1 Block diagram of the second generation of UIN Sunan Kalijaga's UV fluorescence spectro-imaging system

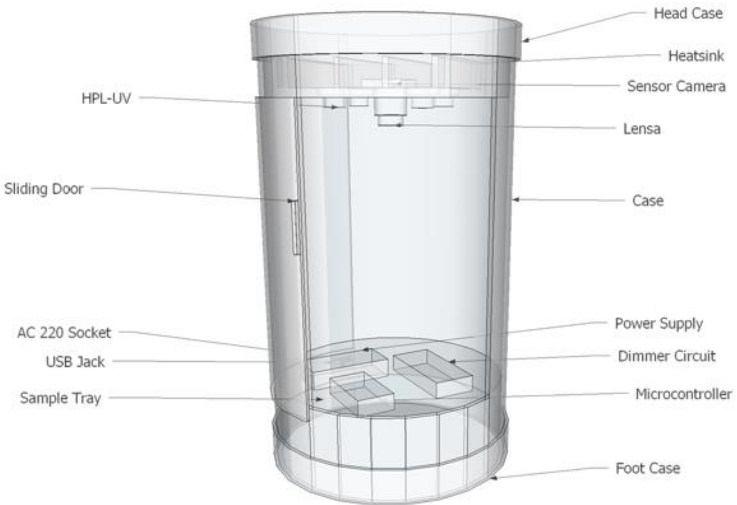

Figure 2 Design of the second generation of UIN Sunan Kalijaga's UV fluorescence spectro-imaging system

Working principle of the system as shown in Figure 1 and 2 begins with connecting it to a 220 volt AC voltage source. The voltage is then conditioned by the power supply subsystem according to voltage requirements of each component. One of the supplied component is the LED driver. The input voltage for LED driver is an AC voltage of 100 to 240 volts, while its output is a DC voltage of 12 volt. The 12 volt DC voltage is used to support the four high-power UVLEDs.

When the four high-power UV-LEDs got a power, they will emit light illuminating the sample. When they illuminate the sample, the atoms in the sample absorb the light energy from them. The absorbed energy will increase energy of atoms in the sample [7].

If the energy absorbed by the atoms in the sample matches their excitation energy, they will be excited from the ground state of $S^{\prime}{ }_{0}$ to a higher level of $S^{\prime}{ }_{1}$. After that, the atoms in the sample relax vibrationally by moving from $S_{1}^{\prime}$ to $S_{1}$. In this condition, some energy will be lost as heat. After reaching state of $S_{1}$, the atoms will return to the ground state of $S_{0}$. When they returns to the ground state of $S_{0}$, the energy is released in the form of light. The released light has greater wavelength than the excitatory light. This phenomenon is known as fluorescence [8] [9] [10] as shown in Figure 3.

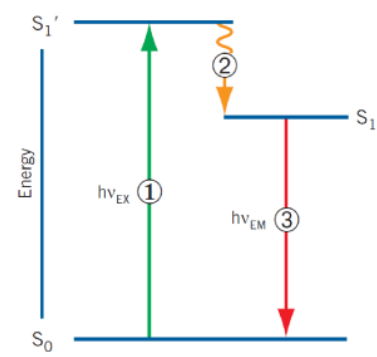

Figure 3 Fluorescence phenomenon

The fluorescence phenomenon generated from the sample by the four high power UV-LEDs is further magnified by the lens. Then, the magnified image is captured by the camera [11] to be forwarded to the computer. 
In the computer, there is an image acquisition software and its processing into three basic colors (redgreen-blue). In addition, there is also a software converting image to spectrum. These softwares were already available on the first generation system. They are still used in the second generation system.

\section{CONCLUSION}

A design of the second generation of UIN Sunan Kalijaga' UV fluorescence spectro-imaging system was made based on a block diagram of the system wich was made previously. The system design will be used as a guide in manufacturing of the second generation system.

\section{REFERENCES}

[1] DPR dan Presiden RI, Undang - Undang Republik Indonesia No. 33 Tahun 2014 Tentang Jaminan Produk Halal. DPR RI dan Presiden Republik Indonesia, Jakarta, 2014.

[2] S.V. Gupta, Measurement uncertainties, Springer, London, Heidelberg Dordrecht, 2012.

[3] F.A. Rakhmadi, R. Rifai, Khamidinal, Design of first generation of Sunan Kalijaga's high power UV-LED fluoerescence spectroscopy system, in: Proceedings of International Conference on Engineering, Science and Applications, 2020, pp. 17-19, DOI: 10.14421/icse.v3.460.

[4] N. Rahmaningrum, F.A. Rakhmadi, I. Fajriati, Analisis tahu terkontaminasi formalin menggunakan sistem spektroskopi, in: Sunan Kalijaga Journal of Physics, 2020, 2(1), pp. 29-33.

[5] G. Haryarta, F.A. Rakhmadi, I. Fajriati, Analisis cilok terkontaminasi boraks menggunakan sistem spektroskopi fluoresensi, in: Sunan Kalijaga Journal of Physics, 2021, 3(1), pp. 28-35.

[6] F.A. Rakhmadi, A. Bahirah, U. Makhfudloh, R. Rifai, A. Kurniawan, Design of light control subsystem based on pulse width modulation to perfect the first generation of UIN Sunan Kalijaga's high power UV-LED fluorescence spectroscopy system, in: Proceeding International Conference on Science and Engineering, 2021, 4, pp. 24-26.

[7] H. Lee, M.S. Kim, W. Lee, B. Cho, Sensors and actuators B: chemical determination of the total volatile basic nitrogen (TVB-N) content in pork meat using hyperspectral fluorescence imaging, in: Sensors Actuators B. Chemical, 2018, 259, pp. 532-539, DOI: 10.1016/j.snb.2017.12.102.

[8] C. Cheubong, E. Takano, Y. Kitayama, et al., Molecularly imprinted polymer nanogel-based fluorescence sensing of pork contamination in halal meat extracts, in: Biosensors and Bioelectronics, 2021, 172, pp. 112775, DOI: 10.1016/j.bios.2020.112775.

[9] H. Jiang, X. Jiang, Y. Ru, J. Wang, L. Xu, H Zhou, Application of hyperspectral imaging for detecting and visualizing leaf lard adulteration in minced pork, in: Infrared Physics \& Technology, 2020, 110, DOI: 10.1016/j.infrared.2020.103467.

[10] V. Rotich, D.F. Al Riza, F. Giametta, T. Suzuki, Y. Ogawa, N. Kondo, Thermal oxidation assessment of Italian extra virgin olive oil using an UltraViolet (UV) induced fluorescence imaging system, in: Spectrochimica Acta - Part A: Molecular and Biomolecular Spectroscopy, 2020, 237, pp. 118373, DOI: 10.1016/j.saa.2020.118373.

[11] L. Sa'adah, F.A. Rakhmadi, R. Widyaningrum, Fluorescence imaging system using high power LED to generate oral auto-fluoerscence of Sprague dawley rat, in: Proceedings of International Conference on Engineering, Science and Applications, 2017, 1, pp. 183-187, DOI: 10.14421/icse.v1.298. 